\title{
MOBILITY IN 2025
}

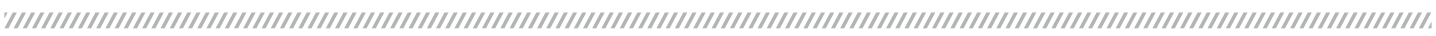

\section{Dear Readers,}

That the automotive future through the next decade would be very different from the world we inhabit today, has become a clichéd statement. But there is no denying the fact that the auto industry worldwide is undergoing a profound transformation, and changes are already visible. Many of the future solutions are confined to labs currently, but there are enough indications on what future mobility would be like.

Products - vehicles in this case - are undergoing a phenomenal amount of change, and so are processes of building them. With climate change concerns rising among consumers and policy makers, there is tremendous amount of pressure on automakers to cut $\mathrm{CO} 2$ emissions. The safety agenda hasn't been stronger than it is now, with OEMs and Tier I players alike chasing 'vision zero' - zero accidents, zero injuries and zero fatalities - with a lot of conviction.

The drive towards electromobility and hybridisation is gathering steam, and the industry will continue to develop solutions to improve efficiency and find feasible alternatives to IC engines. Vehicles are moving towards becoming autonomous in the next 5-7 years, and connected technologies are allowing consumers to use their vehicles as an extension of their private living spaces. The companies that build cars are changing, and there are software companies staking serious claims in mobility of the future. Indeed, consumers who buy vehicles will look significantly different in 10 years from now.

In the wake of growing congestion in urban and semi-urban places, consumers are increasingly looking at convenience. And that is where ride-hailing and ride-sharing services are gaining significant popularity, offering clear evidence that personal mobility is undergoing a transformative shift towards accepting mobility as a service, shifting away from private ownership. One report estimated that the global market for shared vehicles and mobility offerings will grow by $35 \%$ YoY through 2020.

Developments in this regard may not be as pronounced or visible in India as they are in other mature global automotive markets, but there would surely be changes seen in this market as well. India, of course, is contributing in this growth through the engineering and software work that is undertaken in technical \& engineering centres located here.

Meanwhile, at the annual convention of SIAM this year, 'Mobility in 2025 ' is a subject being discussed with utmost priority. Look out for our October 2016 edition for all the details from there.
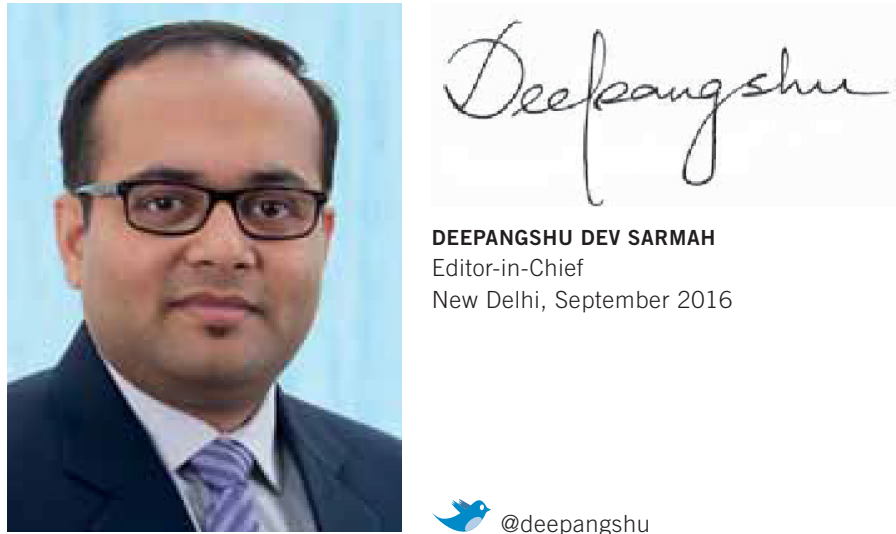

DEEPANGSHU DEV SARMAH

Editor-in-Chief

New Delhi, September 2016 